Original Research Article

\title{
Assessment of quality of life in Indian patients with vitiligo, an observational study
}

\author{
Vedang D. Trivedi, Devang A. Rana*, Kandarp K. Thakkar, Supriya D. Malhotra
}

Department of Pharmacology, Smt. NHL MMC, Ellisbridge, Ahmedabad, Gujarat, India

Received: 28 August 2017

Accepted: 25 September 2017

\section{*Correspondence to:}

Dr. Devang A. Rana,

Email: devangandu@gmail.com

Copyright: () the author(s), publisher and licensee Medip Academy. This is an openaccess article distributed under the terms of the Creative Commons Attribution NonCommercial License, which permits unrestricted noncommercial use, distribution, and reproduction in any medium, provided the original work is properly cited.

\begin{abstract}
Background: Vitiligo is the most common hypopigmentary disorder. In India, the incidence of vitiligo is $0.25-2.5 \%$. It considerably influences the patient's quality-of-life (QoL) and psychological well-being.

Methods: A prospective, observational study was conducted from April 2016 to September 2016 in dermatology outpatient department. Patients clinical characteristic were noted and Quality of life was assessed by using Vitiligo Quality of Life Questionnaires [VQLQ]. During item development, none of the questions were changed according to the results of cognitive and understand ability testing. The scale consisted of 25 questions. The answer to each question was scored as 'never $=1$ ', 'sometimes $=2$ ', 'often $=3$ ' and 'all the time $=4$ ', so the total score ranged between 25 and 100. Higher scores represented more severely impaired quality of life.

Results: We enrolled 78 Vitiligo patients who were attending dermatology department for phototherapy. Out of them 53 were female. Mean age was 37.12 \pm 12.270 . Most common age group was 31-40 years. Mean VLQL score 40.92 \pm 6.081 . Patients were divided based on VQLQ score in Moderate (50-75) and Low score group (25-50). Vitiligo patients presented with symptoms of pain, irritation and itching $(\mathrm{P}<0.0001)$. Vitiligo patients when assessed for feeling domain were significantly embarrassed for their overall look and appearance. (P $<0.0001)$. When Personal relationship domain was analysed physical contact was a major concern $(\mathrm{P}<0.002)$. Patients suffering from Vitiligo were significantly worried about spread of vitiligo and occurrence of cancer $(\mathrm{P}<0.0001)$. Therapy for Vitiligo was time consuming time and was a work place challenge for the patients $(\mathrm{P}<0.0001)$. The reliability of VQLQ in our study was Cronbach's $\alpha$ coefficient was 0.876 .

Conclusions: QoL impairment was relatively high in vitiligo patients. Medical intervention and counselling should focus to improve feelings, personal relationship, anxiety, school/work, leisure and symptom domains.
\end{abstract}

Keywords: Quality of life, Vitiligo, VQLQ

\section{INTRODUCTION}

Vitiligo is a common depigmenting skin disorder characterized by acquired, idiopathic, progressive, circumscribed hypomelanosis of the skin and hair. It occurs worldwide, with an incidence of $0.5 \%$ to $2.0 \%$.

Vitiligo is disfiguring in all races but particularly more so in dark skinned people because of strong contrast. ${ }^{2}$ Vitiligo may entail significant psychosocial consequences. Vitiligo is a social stigma and is associated with a decreased quality of life, especially when lesions are located over the face; thus, it may affect the quality of social and personal life depending on the patient's perception. ${ }^{3}$

In India and perhaps elsewhere also men, women and children with vitiligo face severe psychological and social problems. Many vitiligo patients felt distressed and 
stigmatized by their condition. They attract undue attention from the general public sometimes whispered comments, antagonism and ostracism. The self-image of the vitiligo patients drops considerably and may lead to depression. These patients often develop negative feelings about it, which are reinforced by their experiences over a number of years. Most patients of vitiligo report feelings of embarrassment, which can lead to a low self-esteem and social isolation.,4 Vitiligo lesions over face may be particularly embarrassing and the frustration of resistant lesions over exposed part of hands and feet can lead to anger and disillusionment. Particularly in teenagers, mood disturbances including irritability and depression are common. Patients with vitiligo are very sensitive to the way other perceives them and they will often withdraw, because they anticipate being rejected. Sometimes, strangers and even close friends can make extremely hurtful and humiliating comments. The impact of such factors is profound subjecting them to emotional distress, interference with their employment, or use tensionlessoning, oblivion-producing substances such as alcohol. ${ }^{5}$ Severe depression has been known to lead to suicide attempts. $^{6}$

Quality of life (QoL) is a multidimensional index of the different social, behaviour and cultural factors. Different tools were created for measuring QoL focusing on different conditions and diseases. ${ }^{7-11}$

The purpose of this study is to evaluate the burden of Vitiligo on the quality of life of Vitiligo patients using Vitiligo specific life quality questionnaire developed by Senol et al. ${ }^{11}$

The objective of the study was to assess the impact of the disease on the quality of life of patients suffering from vitiligo.

\section{METHODS}

After the approval of study protocol by Institutional Review Board, a prospective observational study was carried out between April 2016 to June 2016 i.e. 3 months at tertiary care teaching hospital Dermatology Outpatient Department. Vitiligo patients aged more than 18 to 70 years old were included in the study. Informed consent was obtained from all the patients and confidentiality of data was maintained. Unwilling patients, patients below the age of 18 years were excluded from the study. We used Vitiligo specific life quality questionnaire developed by Senol et al. ${ }^{11}$

The questionnaire was classified into 6 headings (Domain):

- $\quad$ Feelings (questions 2,3,4,6,12,13,18,19)

- $\quad$ Personal relationships (questions 20,21,22,25)

- $\quad$ Anxiety (questions 8,10,11,23)

- Work and School (questions 5,7,17)

- $\quad$ Leisure (questions 14,15,16,24)

\section{- $\quad$ Symptom (question 1,9).}

During item development, none of the questions were changed according to the results of cognitive and understandability testing. The scale consisted of 25 questions. The answer to each question was scored as 'never $=1$ ', 'sometimes $=2$ ', ' often $=3$ ' and 'all the time $=4$ ', The VQLQ score is calculated by summing the scores of all the questions, resulting in a maximum of 100 and a minimum of 25. The higher the VQLQ score, the more is the quality of life impaired.

Data were expressed as mean and standard deviation. Comparisons were made using Student's t-tests, and the level of significance was set at $\mathrm{P}<0.05$.

\section{Statistical analysis}

Data was entered into Microsoft Excel 2016 ${ }^{\circledR}$ SPSS $^{\circledR}$ software (version. 21.0 IBM Corporation, California,) was used for statistical analyses. The descriptive analysis was presented in tables as mean and SD for numeric data and frequency (n) and percentage (\%) for categorical data. Fisher's exact test was used to assess gender variation. Reliability of VQLQ was assessed using Cronbach $\alpha$.

\section{RESULTS}

We enrolled 78 Vitiligo patients who attended dermatology department for phototherapy, out of which 53 were female patients. Most common age group in our study was 31-40 yrs (Figure 1). Mean age was $37.12 \pm 12.27 \mathrm{yrs}$.

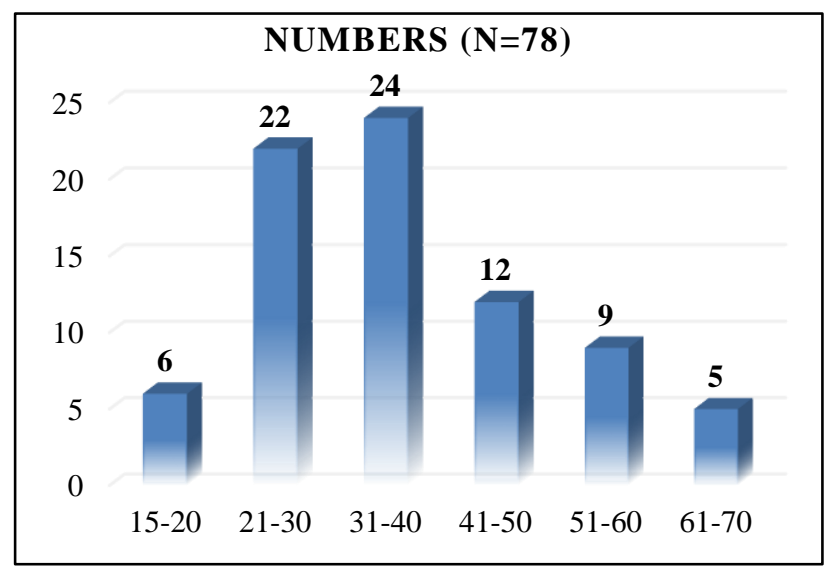

Figure 1: Age wise distribution.

Clinical characteristics: Most commonly involved area was trunk region (32.2\%) as shown in Figure 2.

\section{Vitiligo quality of life questionnaire (VQLQ)}

VQLQ score Mean \pm SD: 40.92 \pm 6.081 . Highest score was 55 and Lowest score was 27. Severity was increased as score increased. We divided total number of patients into 
two groups Mildly affected group (25-50) and Moderately affected group (51-75).

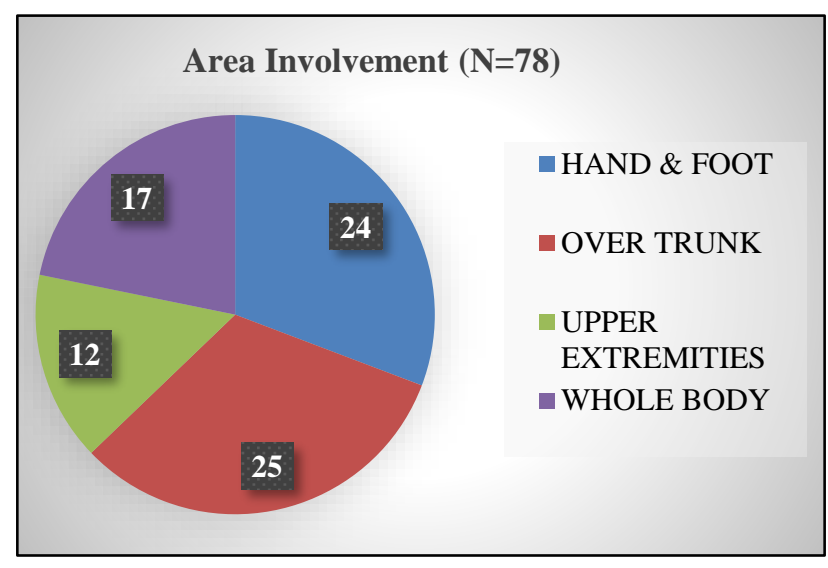

Figure 2: Area involvement.

Vitiligo patients when assessed for feeling domain they were significantly embarrassed for their overall look appearance. ( $\mathrm{P}<0.0001)$ (Table 1).

Table 1: Feeling domain analysis.

\begin{tabular}{|lcll|}
\hline Feelings & Mild & Moderate & P-value \\
\hline Make up (Q4) & 1.54 & 2.57 & 0.0001 \\
\hline $\begin{array}{l}\text { Felt uncomfortable } \\
\text { abt ques (Q18) }\end{array}$ & 1.96 & 2.86 & 0.0001 \\
\hline $\begin{array}{l}\text { Embarrassed d/t } \\
\text { appearance (Q2) }\end{array}$ & 2.30 & 3.14 & 0.0015 \\
\hline $\begin{array}{l}\text { Uncomfortable } \\
\text { looking into mirror } \\
\text { (Q12) }\end{array}$ & 2.48 & 3.86 & 0.0001 \\
\hline $\begin{array}{l}\text { Uneasy about } \\
\text { staring (Q3) }\end{array}$ & 1.58 & 2.14 & 0.0107 \\
\hline $\begin{array}{l}\text { Stayed away from } \\
\text { crowded areas (Q13) }\end{array}$ & 1.11 & 1.14 & 0.835 \\
\hline \begin{tabular}{l} 
Self-esteem (Q6) \\
\hline Isolated (Q19)
\end{tabular} & 2.28 & 2.86 & 0.0131 \\
\hline \begin{tabular}{l} 
(P-value <0.05 was taken as significant value) \\
\hline
\end{tabular}
\end{tabular}

When Personal relationship domain was analysed physical contact was major concern $(\mathrm{P}<0.002)$ (Table 2$)$.

Table 2: Personal relationship domain analysis.

\begin{tabular}{|llll|}
\hline Personal relationship & Mild & Moderate & P-value \\
\hline Intimacy (Q25) & 1.00 & 1.00 & - \\
\hline Partner Quarrel (Q20) & 1.03 & 1.00 & 0.6379 \\
\hline Family issues (Q22) & 1.21 & 1.00 & 0.183 \\
\hline $\begin{array}{l}\text { Avoid Physical } \\
\text { contacts (Q21) }\end{array}$ & 1.03 & 1.29 & 0.0026 \\
\hline
\end{tabular}

(P-value $<0.05$ was taken as significant value)

In Vitiligo patients, they were significantly worried about spread of vitiligo and occurrence of cancer $(\mathrm{P}<0.0001)$ (Table 3).
Table 3: Anxiety domain analysis.

\begin{tabular}{|lccl|}
\hline Anxiety & Mild & Moderate & P-value \\
\hline $\begin{array}{l}\text { Concerns to spread } \\
\text { (Q8) }\end{array}$ & 1.89 & 2.71 & 0.0001 \\
\hline $\begin{array}{l}\text { Anxiety over vitiligo } \\
\text { permanent (Q10) }\end{array}$ & 2.72 & 3.71 & 0.079 \\
\hline Inheritance (Q11) & 1.58 & 1.43 & 0.4513 \\
\hline $\begin{array}{l}\text { Personal items } \\
\text { sharing (Q23) }\end{array}$ & 1.03 & 1.00 & 0.6379 \\
\hline
\end{tabular}

Vitiligo is consuming time and its work place challenge to the patients $(\mathrm{P}<0.0001)$ (Table 4$)$.

Table 4: School/work domain analysis.

\begin{tabular}{|lll|l|}
\hline School/work & Mild & Moderate & P-value \\
\hline Covering clothes(Q5) & 1.01 & 1.29 & - \\
\hline Concealment (Q7) & 1.03 & 1.86 & 0.0001 \\
\hline $\begin{array}{l}\text { Challenges faced } \\
\text { (Q17) }\end{array}$ & 1.01 & 1.43 & 0.0001 \\
\hline
\end{tabular}

(P-value $<0.05$ was taken as significant value)

Vitiligo patients felt that disease consumes time, money at the cost of time spend in hobbies and with family (Table $5)$.

Table 5: Leisure domain analysis.

\begin{tabular}{|llll|}
\hline Leisure & Mild & Moderate & P-value \\
\hline Vacation plans (Q15) & 1.00 & 1.00 & - \\
\hline $\begin{array}{l}\text { Free time, Ur } \\
\text { hobbies (Q16) }\end{array}$ & 1.00 & 1.00 & - \\
\hline $\begin{array}{l}\text { Sun exposure/ } \\
\text { Protection (Q14) }\end{array}$ & 2.44 & 3.14 & 0.0017 \\
\hline Compliance (Q24) & 2.46 & 3.43 & 0.0006 \\
\hline
\end{tabular}

(P-value $<0.05$ was taken as significant value)

Vitiligo patients presented with symptoms of pain, irritation and itching $(\mathrm{P}<0.0001)$ (Table 6).

The reliability of VQLQ in our study was Cronbach's $\alpha$ coefficient was 0.876 considered as good. QoL impairment was relatively high in vitiligo patients.

Table 6: Symptom domain analysis.

\begin{tabular}{|llll|}
\hline Symptom & Mild & Moderate & P-value \\
\hline Pain, Irritation (Q1) & 2.69 & 3.71 & 0.0001 \\
\hline Skin cancer (Q9) & 1.32 & 2.14 & 0.0001 \\
\hline
\end{tabular}

\section{DISCUSSION}

Vitiligo is an important skin disease having major impact on the quality of life of patients suffering from vitiligo. Appearance of skin condition is important for an individual self-image, and any pathological alteration can have psychological consequences. 
So, our study was aimed to assess the impact of Vitiligo on the quality of life of patients.

\section{Demographic characteristics}

Most common age group in our study was between 31-40 yrs that was similar to a study done by Hedayat K et al. ${ }^{12}$ This suggests that vitiligo is highly prevalent disease below age of 40 years.

There was female preponderance in our study which is also seen in other studies.

Although vitiligo affects both sexes equally, most of the studies show a female preponderance. ${ }^{13-15}$ The cause of female preponderance presenting in dermatology clinic is probably because of greater cosmetic awareness and the impact of the disease on their social life. ${ }^{16}$ This is due to autoimmune nature of the disease, which are more prevalent in females.

The reasons for the high prevalence in women are unknown, but circumstantial evidence links autoimmune diseases with preceding infections. Sex hormones may further amplify this hyperimmune response to infection in susceptible persons, which leads to an increased prevalence of autoimmune diseases in women. ${ }^{17}$ People suffering from certain autoimmune disease such as hyperthyroidism are more likely to get vitiligo than people who don't have any autoimmune disease. Scientists don't know why vitiligo is connected with these diseases. However, most people with vitiligo have no other auto immune disease. $^{18}$

\section{Area involved}

In our study, most commonly involved area was over trunk region $(32.2 \%)$ followed by hand and foot region.

\section{Psychological and social impact using VQLQ}

In our study Mean VLQL score was 40.92 \pm 6.08 which showed mild deterioration of quality of life. Highest score was 55 and Lowest score was 27. Patients were divided based on VQLQ score in Moderate (50-75) and Low score group (25-50). No. of patients belonging to moderate group was 5 patients and in low score group was 73 patients.

\section{Feeling domain}

Vitiligo patients when assessed for feeling domain, were significantly embarrassed for their overall look appearance. Patients were more psychologically concerned about their appearance, the had low self-esteem and they often felt uncomfortable when they were asked about their disease. $(\mathrm{P}<0.001)$. Similar results were shown in Porter et al, Prasad et al, Mattoo et al, Finlay et al studies. ${ }^{2,4,19,20}$ Vitiligo patients were having negative beliefs about their overall look. Concern regarding their looking different from others and getting a stare was of a concern in patients suffering from vitiligo. $(\mathrm{P}<0.05)$. Suffering from the disease did not make them stay away from crowed areas like public transportation, shopping centres, etc. $(\mathrm{P}=0.835)$.

\section{Personal relationship domain}

When Personal relationship domain was analysed physical contact was major concern $(\mathrm{P}<0.05)$. This result was a similar to previous study done by Porter et al, which reported $23 \%$ decline in physical contact. ${ }^{21}$ Vitiligo patients reported to have no issues with their partner and family issues with $\mathrm{P}=0.638$ and $\mathrm{p}=0.183$, respectively.

\section{Anxiety domain}

VQLQ evaluated domain of anxiety also, in our study patients were anxious for the spread of the lesions to other body parts and its permanent complications, $(\mathrm{P}<0.05)$ but statistically no difference was found in high score group and low score group for inheritance to their children and article sharing. This finding was also reciprocated as in Tunision study and Belgian study. ${ }^{22,23}$ Vitiligo patients were apprehensive due to their lesions on body parts. They were never afraid of vitiligo being permanent $(\mathrm{p}=0.079)$ and never worried about inheritance of vitiligo to their children $(\mathrm{p}=0.451)$. Patients of vitiligo never felt uneasy about sharing personal items with the household members. $(\mathrm{P}=0.638)$.

\section{School/ work domain}

Vitiligo is consuming time for clothing to cover lesions and it is considered as a work place challenge to the patients $(\mathrm{P}<0.005)$. This finding was also reciprocated in Porter et al studies that in an attempt to hide their vitiligo lesions, many patients wore adapted clothing and applied large quantities of cosmetics. ${ }^{24-26}$

\section{Leisure domain}

In our study, most of the patients felt that disease consumes time, money at the cost of time spent in hobbies and with family. Also, patients felt confined to home and avoided sun exposure. $(\mathrm{P}<0.05)$ Patients of Vitiligo had lesser free time for enjoyment. ${ }^{27}$

\section{Symptom domain}

Vitiligo patients presented with symptoms of pain, irritation and itching $(\mathrm{P}<0.0001)$. A similar study of Linthorst Homan et al, reported pruritus in $20 \%$ of vitiligo patients. ${ }^{28}$ Patients of Vitiligo felt uneasiness due to symptoms. Melanin pigment produce by melanocytes use to absorb ultraviolet light (UV) and thus prevent DNA damage. Melanin also works as a Scavenger of free radicals in human body. Hence lack of epidermal melanin increase susceptibility to skin cancers and is an indicator of aging skin. ${ }^{18}$ 


\section{Reliability of VQLQ}

The reliability of VQLQ in our study was Cronbach's $\alpha$ coefficient was 0.876 which is considered as good. QoL impairment was relatively high in vitiligo patients.

This was a first study of its kind done at our set up which evaluated impact of vitiligo on quality of life. The patient Quality of Life (QoL) was measured at the time they were presented for treatment at dermatology outpatient department. They were receiving standard treatment like PUVA, Narrow band UV-A, UV-B. The authors write the conclusion feeling domain was most severely affected in comparison to personal relationship and leisure domain.

The limitation to this study is that VLQI could be applied to larger patient groups involving various severities of the disease all skin types can increase its value as a scale. The first step in helping vitiligo patients who felt isolated and who isolate themselves from the community is to understand how severely their quality of life is impaired. We could not measure Quality of Life with respect to Treatment and Improvement. Comparison with normal population was not done. Compliance for regular longterm visits for PUVA/narrow band UVB therapy, side effects of immunosuppressive therapies, long term risk of photoaging and carcinogenesis with phototherapy are other limitations for vitiligo patients. The VLQI, which has been developed for this purpose, has been proven to better reflect the quality of life of vitiligo patients than the DLQI and to be more commonly preferred by them. The VLQI is ready for use in our clinical practice and can be used in further epidemiologic studies where temporal change in the scores during treatment should be observed to further test sensitivity.

\section{CONCLUSION}

In vitiligo, Counselling can help improve body image, selfesteem, and quality of life of patients with vitiligo. ${ }^{29}$ There are two types of strategies to counter vitiligo psycho-social impact. Behavioural strategies focused on the problems and involved avoidance of situations and concealment of the vitiligo lesions. These though helpful in the short term, caused restriction in activities. The cognitive strategies focused on the emotions. It dealt with modifying the patients felting of being different and their interpretation of others' behaviour. With this, a strategy of acceptance of difference was attained over a period, which was facilitated by social support; however, it was difficult to maintain this strategy. ${ }^{30}$ In an attempt to hide their vitiligo lesions, many patients wore adapted clothing and applied large quantities of cosmetics. ${ }^{24-26}$ There is a need for accessible, accurate, community-based education about the natural history of vitiligo, the effectiveness of treatments and its expected duration. The provision of such information facilitates therapeutic selection by the patient, enhancing their understanding of treatment options and influencing the public attitude towards this disease.

\section{ACKNOWLEDGEMENTS}

Authors would like to express their gratitude to Department of Dermatology and their Sincere thanks to our Dean Dr. Pankaj R Patel.

\section{Funding: No funding sources}

Conflict of interest: None declared

Ethical approval: The study was approved by the Institutional Ethics Committee

\section{REFERENCES}

1. Yaghoobi R, Omidian M, Vitiligo BN. a review of the published work. J Dermatol. 2011;38:419-31.

2. Mattoo SK, Handa S, Kaur I, Gupta N, Malhotra R. Psychiatric morbidity in vitiligo: prevalence and correlates in India. J Eur Acad Dermatol Venereol. 2002;16:573-8.

3. Tarlé RG, Nascimento LM, Mira MT, Castro CC. Vitiligo -part 1. An Bras Dermatol. 2014;89:461-70.

4. Finlay AY. Quality of life indices. Indian J Dermatol Venereol Leprol. 2004;70:143-8.

5. Ginsburg IH. The psychological impact of skin diseases: An overview. Clin 1996, 14:473-484.

6. Cotterill JA and Cunliffe WJ: Suicide in dermatological patients. $\mathrm{Br} \mathrm{J}$ Dermatol. 1997;137(2):246-50.

7. Gupta V, Sreenivas V, Mehta M, Khaitan BK, Ramam M. Measurement properties of the Vitiligo Impact Scale-22 (VIS-22), a vitiligo-specific quality-of-life instrument. British Journal of Dermatology. 2014 Nov 1;171(5):1084-90.

8. Krishna GS, Ramam M, Mehta M, Sreenivas V, Sharma VK, Khandpur S. Vitiligo impact scale: An instrument to assess the psychosocial burden of vitiligo. Indian Journal of Dermatology, Venereology, and Leprology. 2013 Mar 1;79(2):205.

9. Finlay AY, Khan GK. Dermatology Life Quality Index (DLQI) -a simple practical measure for routine clinical use. Clin Exp Dermatol. 1994;3:210-6.

10. Anderson RT, Rajagopalan R. Development and validation of a quality of life instrument for cutaneous diseases. J Am Acad Dermatol. 1997;37(1):41-50.

11. Şenol A, Yücelten AD, Ay P. Development of a Quality of Life Scale for Vitiligo. Dermatology 2013;226:185-90.

12. Hedayat K, Karbakhsh M, Goodarz A, Fakour Y. Quality of life in patients with vitiligo: a crosssectional study based on Vitiligo Quality of Life index (Viti QoL) Health and Quality of Life Outcomes. 2016;14:86.

13. Sarin RC, Kumar AJ. A clinical study of vitiligo. Indian J Dermatol Venereal Leprol. 1977;43:311-4.

14. Howitz J, Brodhagen H, Schwartz M, Thomsen K. Prevalence of vitiligo. Arch Dermatol. 1977;113:4752.

15. Bar S, Feiwel M, Chanarin I. Vitiligo and its aetiological relationship to organ specific autoimmune disease. Br J Dermatol. 1969;81:83. 
16. Martis J, Bhat R, Nandakishore B, Shetty JN. A clinical study of vitiligo. Indian J Dermatol Venereol Leprol. 2002;68:92-3.

17. DeLisa F, Rose NR. Women and Autoimmune Diseases, Emerging Infectious Diseases. 2004;10(11):2005-11.

18. Singh S, Twara T, Singh OP. Psychosocial Aspects of Vitiligo. Br J Med Health Res. 2016;3(2):1-10.

19. Porter J, Beuf AH, Nordlund JJ, Lerner AB. Psychological reaction to chronic skin disorders: a study of patients with vitiligo. Gen Hosp Psychiatry. 1979;1:73-7.

20. Parsad D, Dogra S, Kanwar AJ. Quality of life in patients with vitiligo. Health Qual Life Outcomes. 2003;1:58.

21. Porter JR, Beuf AH, Lerner AB, Nordlund JJ. The effect of vitiligo on sexual relationships. J Am Acad Dermatol. 1990;22:221-2.

22. Mechri A, Amri M, Douarika AA, Ali Hichem BH, Zouari B, Zili J. Psychiatric morbidity and quality of life in vitiligo: a case controlled study [in French]. Tunis Med. 2006;84(10):632-5.

23. Ongenae K, Van Geel N, De Schepper S, Naeyaert JM. Effect of vitiligo on self reported health-related quality of life. Br J Dermatol. 2005;152(6):1165-72.

24. Porter J, Beuf A, Nordlund JJ, Lerner AB. Personal responses of patients to vitiligo: The importance of the patient-physician interaction. Arch Dermatol. 1978;114:1384-5.
25. Porter J, Beuf AH, Nordlund JJ, Lerner AB. Psychological reaction to chronic skin disorders: A study of patients with vitiligo. Gen Hosp Psychiatry. 1979;1:73-7.

26. Porter J, Beuf AH, Lerner A, Nordlund J. Response to cosmetic disfi gurement: Patients with vitiligo. Cutis. 1987;39:493-4.

27. Belhadjali H, Amri M, Mecheri A, Doarika A, Khorchani H, Youssef M, et al. Vitiligo and quality of life: A case-control study. Ann Dermatol Venereol. 2007;134:233-6.

28. Linthorst Homan MW, Spuls PI, de Korte J, Bos JD, Sprangers MA, van der Veen JP. The burden of vitiligo: Patient characteristics associated with quality of life. J Am Acad Dermatol. 2009;61:411-20.

29. Papadopoulos L, Bor R, Legg C. Coping with the disfiguring effects of vitiligo: A preliminary investigation into the effects of cognitive-behavior therapy. Br J Med Psychol. 1999;72:385-96.

30. Thompson AR, Kent G, Smith JA. Living with vitiligo: Dealing with difference. Br J Health Psychol. 2002;7:213-25.

Cite this article as: Trivedi VD, Rana DA, Thakkar KK, Malhotra SD. Assessment of quality of life in Indian patients with vitiligo, an observational study. Int J Basic Clin Pharmacol 2017;6:2635-41. 


\section{ANNEXURE-I}

VLQI (Vitiligo Life Quality Index).

Please answer the questions below in light of the last week.

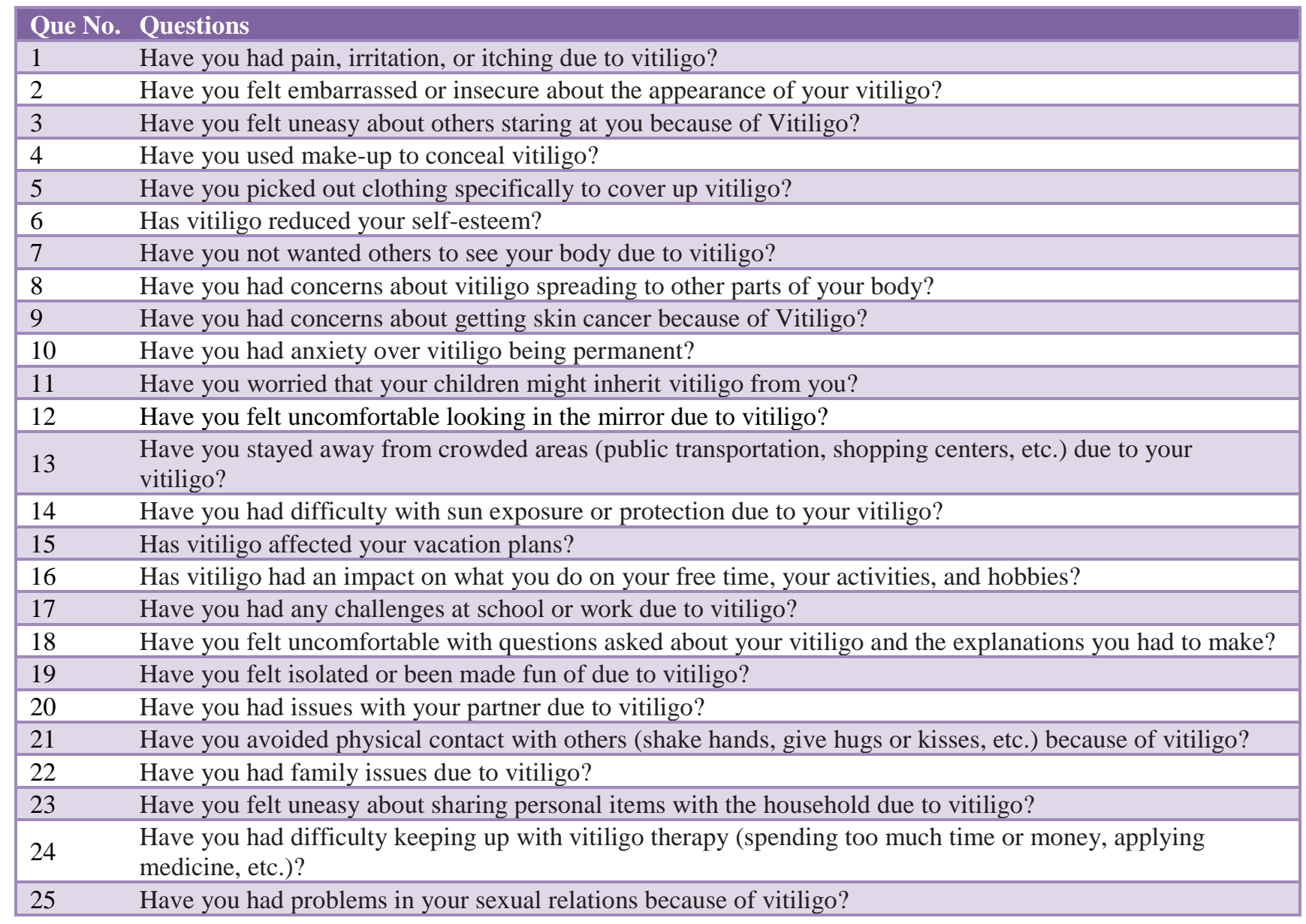

